\title{
Health and safety problems associated with long working hours: a review of the current position
}

\author{
Anne Spurgeon, J Malcolm Harrington, Cary L Cooper
}

\begin{abstract}
The European Community Directive on Working Time, which should have been implemented in member states of the European Community by November 1996, contains several requirements related to working hours, including the right of employees to refuse to work more than 48 hours a week. The United Kingdom government attempted to oppose the Directive, arguing that there is no convincing evidence that hours of work should be limited on health and safety grounds. Much of the research in this area has focused on the problems of shiftworking and previous reviews have therefore tended to emphasise this aspect of working hours. However, there is much less information about the effects of overtime work, which is a central element of the terms of the Directive. This paper reviews the current evidence relating to the potential effects on health and performance of extensions to the normal working day.
\end{abstract} Several gaps in the literature are identified. Research to date has been restricted to a limited range of health outcomesnamely, mental health and cardiovascular disorders. Other potential effects which are normally associated with stress-for example, gastrointestinal disorders, musculoskeletal disorders, and problems associated with depression of the immune system, have received little attention. Also, there have been few systematic investigations of performance effects, and little consideration of the implications for occupational exposure limits of extensions to the working day. Existing data relate largely to situations where working hours exceed 50 a week and there is a lack of information on hours below this level, which is of direct relevance to the European Community proposal. Finally, it is clear from investigations relating to shiftwork that a range of modifying factors are likely to influence the level and nature of health and performance outcomes. These include the attitudes and motivation of the people concerned, the job requirements, and other aspects of the organisational and cultural climate. It is concluded that there is currently sufficient evidence to raise concerns about the risks to health and safety of long working hours. However, much more work is required to define the level and nature of those risks.

(Occup Environ Med 1997;54:367-375)

Keywords: long working hours; health and performance

By November 1996, the European Community Directive on Working Time ${ }^{1}$ should have been implemented by all member states of the European Community. This measure has, as its legal basis, Article 118A of the Treaty of Rome, which is intended to encourage proposals for "improvements especially in the working environment as regards the health and safety of its workers". The United Kingdom government attempted to oppose the introduction of the Directive and challenged the legal basis of the original proposal arguing that it should be implemented under Employment Law rather than Health and Safety Legislation. The significance of this is that employment law requires unanimous agreement for its implementation, unlike health and safety legislation which may be passed on majority voting.

The United Kingdom's challenge was, however, overruled by the European Court of Justice, which means that the Directive should now be implemented in the United Kingdom. However, the British government continues to voice its objections. The basis for such objections seems to be primarily an economic one-namely, that certain aspects of the Directive would impose unacceptable restrictions on employers and hence reduce the competitiveness of British industry. In particular there is concern about the section of the Directive which gives employees the legal right to refuse to work more than 48 hours a week. Associated with this are the requirements for a daily rest period of 11 consecutive hours in each 24 hour period and a minimum weekly rest period of one day. In support of their argument, the United Kingdom government maintains that 
there is no convincing evidence to support the view that long working hours are damaging to either the health or the safety of employees.

What, therefore, is the current status of the scientific and medical evidence relating to the effects of working long hours? Is there adequate information available in this area? If so does this support the United Kingdom position, or is it actually the case that there are insufficient data on which to base firm conclusions? The overwhelming emphasis of research in this field to date has been on the effects of shiftworking and not surprisingly earlier reviews have tended to emphasise this. ${ }^{2}{ }^{3}$ However, although clearly of relevance and importance to the Directive as a whole, most of the evidence derived from the field of shiftwork research is not strictly applicable to the question of long hours or overtime. Shiftworking, or any work which involves phase shifting, invariably results in the disruption of circadian rhythms. This presents a more complex situation than that where stress and fatigue result from an extension of the working day. Similarly, 12 hour shifts which might, in one sense, be viewed as an extension of the working day should also be considered in the category of shiftworking. The systematic and often rotational nature of the work pattern in 12 hour shiftworking, together with the different motivational and attitudinal factors involved, merit separate consideration. (These reviews ${ }^{2} 3$ include such shiftwork.) Our review therefore is concerned exclusively with the information available on the health and performance effects of overtime work. This is defined as extending the "normal" work daythat is, beyond the traditional eight hours which are usually worked between 900 am and $500 \mathrm{pm}$ or between 800 am and $400 \mathrm{pm}$ for five or six days a week. It includes overtime working in the evenings, at weekends, and occasionally during holiday periods.

Relevant papers for this review were identified from seven databases-namely, ABI/ INFORM, CINAHL, CISDOC, HSELINE, medline, NIOSHTIC, and PsycLIT covering the period from 1975. These databases had been identified as being those which were relevant in the preparation of a previous review by JMH. ${ }^{3}$ Only those papers which referred to long hours, as defined above, were considered. However, papers concerned with shiftworking were also examined for any additional reference to long hours in the course of the study in question. We had previously aquired certain other papers - namely, those relating to some very early studies. ${ }^{4-6}$

\section{Current working hours}

There is considerable international variation in attitudes and practices relating to working hours, even within the developed world. In the United Kingdom the tendency is for employees to work longer hours than comparable groups in other European states, averaging a total of 44.7 working hours a week as opposed, for example, to 39.9 in Germany and 39 in Denmark and the Netherlands. ${ }^{7}$ Recent data ${ }^{8}$ show that the United Kingdom has about twice as many employees as any other country in the
European Union who work more than 48 hours in a normal week. In a recent survey carried out by Austin Knight ${ }^{9}$ which sampled employees from 22 large United Kingdom organisations, two thirds reported regularly working more than 40 hours a week and one quarter more than 50 hours a week, despite having contracted hours of between 35 and 37 hours. A survey carried out by the United Road Transport Union of the hours and conditions of 640 professional lorry drivers in the United Kingdom found that the average working week of those sampled was 62 hours. ${ }^{10}$ In the United States the average contracted working week was 37.5 hours in 1990, although with overtime the working week of the average male American worker was nearer 41 hours. During the same period the average Japanese worker worked a contracted 41 hour week, but, in addition, averaged nearly 36 hours of overtime a month. ${ }^{11}$ Japan tends to be regarded as an example of the extreme in terms of long hours, but some of the data recently gathered in the United Kingdom suggest that conditions for at least some groups of British workers are not so different from those of the average Japanese.

A growing trend which is not always reflected in official statistics is the tendency for professionals and managers in particular to work unpaid overtime to deal with excessive workloads. Data to support this are generally collected and published by Unions. A survey carried out by the National Association of Teachers in Further and Higher Education, for example, showed that lecturers in further education worked averages of 46.7 to 55.9 hours a week on and off site. ${ }^{12}$ Another survey by the Manufacturing, Science and Finance Union of staff in charities and non-profit making organisations found that most were working up to 10 hours a week beyond their contractual obligations without remuneration. ${ }^{12}$

Many such surveys also highlight the stress experienced by workers who reported long hours. It is arguable that the relation between hours of work and ill health is mediated by stress, in that long hours act both directly as a stressor, in increasing the demands on a person who attempts to maintain performance levels in the face of increasing fatigue, and indirectly by increasing the time that a worker is exposed to other sources of workplace stress. A high level of stress has long been regarded as a contributory factor in the development of certain types of psychiatric problems, ${ }^{13}$ coronary heart disease, ${ }^{14}$ musculoskeletal problems, ${ }^{15}$ and symptoms associated with gastrointestinal disorders. ${ }^{16}$ All of these have been considered in relation to shiftwork. However, examination of the literature relating exclusively to long hours shows that investigations have so far largely been limited to mental health and cardiovascular effects. There is also a limited but growing literature on the consequences for performance and safety, ${ }^{17-22}$ although little information on the implications for control of chemical and other exposures. ${ }^{23}$ 


\section{Mental health disorders}

Despite evidence of an association between shiftworking and increased psychiatric morbidity, ${ }^{24}{ }^{25}$ particularly among shiftworkers who regularly work more than 48 hours a week, ${ }^{26}$ there is a dearth of studies which focus exclusively on the relations between regular overtime working and mental health status. However, several studies have discussed long hours in the context of a range of other potential stressors and their effects on psychological wellbeing. In these studies, psychological health is defined and measured in various ways, ranging from specific measures of psychiatric status to the incidence of non-specific symptoms or maladaptive behaviour.

In one of the earlier studies, Schmitt et al collected data on unexplained physical symptoms in over 800 subjects from eight American organisations where outbreaks of mass psychogenic illness had occurred. ${ }^{27}$ Small but significant correlations were found between the number of hours of overtime worked and the number of symptoms reported during an outbreak of illness in the organisation. However, working hours was only one of a range of variables included, many of which showed a similar relation with symptom reporting. Not surprisingly the source of the problem was judged to be multifactorial. Also, the authors note the atypical nature of the respondents and the lack of comparison with workers in non-affected companies.

More recently several studies have used direct measures of mental health with standard measurement tools. A study of music therapists working with mentally handicapped children ${ }^{28}$ examined the relation between several predictor variables, including hours worked and the concept of "burn out", a condition characterised in the psychological literature as a state of mental and physical exhaustion. ${ }^{29}$ There was no significant association between the number of hours worked a week and the various indicators of burn out. The response rate was low however-less than 50\%-raising the possibility of underreporting, as those failing to cope may have been reluctant to put this on record. Also, few of those who replied worked more than 50 hours a week, most working between 40 and 49 hours. It should perhaps be noted that nearly $80 \%$ of the respondents had worked for less than five years as therapists and that indicators of exhaustion were more pronounced in those who had worked longer, suggesting the possibility of a cumulative effect in a job which was clearly emotionally demanding.

A study of the mental health of urban bus drivers ${ }^{30}$ also examined, with a standard measure of psychiatric status, ${ }^{31}$ a range of possible sources of occupational stress. Mental health scores were poor compared with those of a male normative sample from general practice, and "family problems associated with long working hours" was identified as a significant factor related to occupational stress. Again, however, many other work stressors were noted which seemed to be of equal or greater importance for this group.
Finally a study of British accountants ${ }^{32}$ identified a factor of quantitative workload, of which working long hours was a major component, which was significantly related to psychological wellbeing as measured by two standard measures. ${ }^{33}{ }^{34}$ Two other important factors identified in this group were administrative problems and the level of social support.

Perhaps the country which has most obviously developed a culture of overtime working in recent years, and hence concern about its potential problems is Japan. A study which examined the determinants of mental health in a large sample of factory workers, ${ }^{35}$ again with a standard measure,$^{34}$ found that working time of more than nine hours a day alongside lifestyle factors such as physical exercise and nutritional balance was significantly related to the overall level of psychological distress. Interestingly there were some differences between the sexes in that adverse effects of long hours were more noticeable in women than men, presumably because of the additional domestic stressors experienced by women. A study in Canada ${ }^{36}$ highlighted the importance of taking into account the domestic load of women when calculating weekly working hours. Female hospital workers in this study had an average professional working week of just over 32 hours, but also a domestic working week of 19 hours. Reports of exhaustion and insomnia were associated primarily with the duration of the domestic working week. Hall and co-workers ${ }^{37}$ also noted that the interactive effects between "home work" and "paid work" on psychosomatic symptoms were more pronounced for women than for men.

Three studies have examined the prevalence of what are termed "maladaptive behaviours" in response to stress. This refers to types of behaviour frequently used as coping strategies which are primarily aimed at avoidance of the problem. Such strategies are unlikely to result in long term solutions and frequently lead to further health problems. Typical examples are increased smoking and substance misuse. Raggatt $^{38}$ found that in long distance coach drivers in Australia long driving hours provided the single best predictor of stimulant use and sleep disturbance. Further, as might be expected, these behaviours were predictive of the level of symptom reporting, particularly stress related problems such as anxiety and depression, musculoskeletal symptoms, and of visits to doctors. Average weekly hours in this sample were under 47 , although the range was 30 to 70 hours. There was no relation between maladaptive behaviour and the number of hours driving at night or the number of years driving coaches, suggesting that the actual time spent behind the wheel was the important factor, and that, in this occupational group, the effect was immediate rather than cumulative. Some tentative support for these findings are provided by the results of a survey commissioned by a large United Kingdom telecommunications company. ${ }^{39}$ Over the three years of the survey, most respondents were working in excess of their weekly contracted hours of around 42 with nearly $18 \%$ working more than 50 hours a 
week. In this group, $28 \%$ reported heavy drinking, smoking, or drug misuse compared with $8 \%$ of those working their contracted hours only, although these behaviours were not further defined and may have been interpreted differently by different respondents. Those working longer hours, however, also reported a higher frequency of a range of stress related symptoms - for example headaches, sleep disturbance, and relationship problems.

A study carried out in a very different setting among male members of an Israeli kibbutzim ${ }^{40}$ focused particularly on smoking behaviour. More than eight hours of work a day, and what was termed "addiction to work", was positively related to smoking intensity and negatively related to stopping smoking. Other studies have shown that stress contributes to intensity of smoking. ${ }^{41}$ In the Israeli study the main source of stress seemed to be long working hours, although there is perhaps some suggestion that personality factors and also social factors in this highly self selected group, may have contributed both to long hours and smoking behaviour. Social and cultural influences may have a significant part to play both in determining the hours people choose to work and the form of resulting maladaptive behaviour. Studies in Japan for example, have often focused on alcohol consumption, ${ }^{42}$ which seems to have become an integral part of the long hours culture.

Alongside those studies which have specifically assessed mental health status or maladaptive behaviour are some which have examined the relative importance of various factors, including long hours, in producing self reported stress in different populations. Here an assumption must be made that the presence of stress equates to the presence of mental health problems, although mental health is not measured directly. Most studies treat work overload and long hours as separate factors, although they might be viewed as overlapping to some extent. Populations in which working long hours has been identified as a significant source of stress include hospital doctors, ${ }^{43}$ police officers in the United Kingdom, ${ }^{44}{ }^{45}$ and managerial $^{46} 47$ and clerical personnel ${ }^{46}$ in America and Japan. Working overtime was identified as a much greater source of stress by managerial and professional groups than by clerical groups in the American study, ${ }^{46}$ although no figures for actual hours worked were given or mention made of home working. In the Japanese study of managerial staff, ${ }^{47}$ more than $40 \%$ worked more than 10 hours a day, with more than $30 \%$ of section chiefs working more than 11 hours a day.

In two studies of police officers, ${ }^{44} 45$ no figures are given for average hours, and it should perhaps be borne in mind that in these cases shiftworking was a complicating factor, which is outside the scope of this review. Similarly, many studies have shown stress problems and poor mental health in junior hospital doctors, ${ }^{48}$ an occupational group in which extended hours have long been the norm. Here, however, the situation is one which includes night working and hours which are so excessive as to seriously restrict the time available for sleep. The issue of doctors' hours is clearly one of major importance, particularly in the light of suggestions that doctors should be excluded from the terms of the Directive. However, data from this atypical group are of perhaps limited relevance in examining specifically the effect of overtime worked by employees in other sectors, and they will not therefore be discussed in detail here.

Several questions arise when one considers only those studies which have been concerned with "normal" overtime. Firstly, the relation between hours worked and mental health is never studied directly and in isolation, but rather within the context of the investigation of numerous potential sources of occupational stress, which may together lead to varying degrees of psychological disturbance. In this context long hours have often been found to be an important factor relative to some others studied, but not necessarily the only or the most important factor. Further, it is difficult to determine whether long hours are themselves a direct source of stress or whether they simply serve to increase the impact of other stressors. In practice it is difficult to separate the effects of long hours from those of occupational stress in general, as by its very nature, overtime usually occurs in situations of work overload.

Notwithstanding this, another important issue relates to the effects of individual differences in motivation and working conditions. Most obviously, sex differences in response to overtime have been highlighted. Also, Bliese and Halverson ${ }^{49}$ have drawn attention to the importance of choice in determining a person's response to long hours. Effects on wellbeing may be much less in those electing to work overtime, because of internal commitment or enjoyment of work, than in those compelled to do so because of work overload or company pressure. They argue that investigations which rely on the summing of individual responses may not accurately reflect the relation between hours of work and wellbeing in the work groups as a whole, as the group will contain members who both work more overtime than others and have varying reasons for doing so.

Watanabe et al, for example, examined the relation between health status and working conditions in operators of visual display terminals ${ }^{50}$ and found an association between self rated symptoms of depression and long working hours. However, long hours were also associated with personality factors (type A characteristics) and with attitudes to computers, with those describing themselves as "technocentred" working longer than others. In this case overtime workers may have been a self selected group, making it difficult to draw conclusions about the direction of any causal relation between long hours and mental health problems.

Work conditions during overtime may differ considerably from those during normal working hours. Haugland, ${ }^{51}$ in a small scale study of stress and performance effects in 26 academic personnel working beyond the end of the 
normal day, found that stress levels decreased during overtime. The people themselves attributed this to a period of uninterrupted quiet when tasks could be completed quickly and efficiently. This raises a wider question of whether the effects of long hours can be generalised across populations with different situations, demands, and cultural norms. Further, it points to the need to investigate in more detail the effects, particularly on performance and safety, of working overtime on any single day. Published studies to date have focused on the cumulative effects of the total number of extra hours in a working week.

Finally, if one accepts that long hours may contribute to occupational stress and its consequences, directly or indirectly, at what level of overtime do effects begin to occur? Overall, the existing data tend to support the view that weekly hours which exceed 50 are associated with increased occupational stress, both in terms of subjective reports and behavioural responses. However, it should be noted that most of the studies in which effects were found contained a high percentage of people who worked well in excess of this. Further, many studies have been concerned with somewhat unusual or highly self selected groups. The adoption of 50 hours as a threshold on this basis therefore might be viewed as somewhat arbitrary or perhaps cautious.

\section{Cardiovascular disorders}

If one assumes that long working hours are a major source of occupational stress, it is reasonable to expect an association between long hours and cardiovascular disorders. The mechanisms underlying the association between stress and coronary heart disease are thought to relate to multiple and sustained increases in heart rate and blood pressure as a result of neuroendocrine activation, ${ }^{52}$ although individual difference in cardiovascular reactivity in response to acute stress have long been recognised. ${ }^{53}$ In the $1960 \mathrm{~s}$, increasing concern over the levels of coronary heart disease in developed countries produced several studies primarily aimed at identifying important risk factors. Forty years ago the concept of occupational stress was in its infancy, but fortuitously this offers certain advantages in the present context. Two studies at that time elected to define and measure occupational stress solely in terms of working hours, an approach which would be unlikely today.

Russek and Zohman ${ }^{54}$ found that in 100 coronary patients under the age of 40 the presence of severe occupational strain-that is, very long working hours - was more than four times that in a control group. Seventy one per cent of the coronary group had for a prolonged period, either worked both days and evenings or had worked more than 60 hours a week. Subsequently Buell and Breslow ${ }^{55}$ analysed Californian occupational mortality data for a three year period and concluded that the mortality risk from coronary heart disease was greater in men under the age of 44 who worked more than 48 hours a week in certain occupations notably those not involving heavy physical work, a factor which seemed to offer some protection. Further evidence of an increased cardiovascular mortality risk associated with long hours was provided by a United Kingdom study of employees of the Bell Telephone Company during the 1960 s who worked full time and also attended night school. ${ }^{56}$

By contrast the results of a study in Sweden in the $1960 \mathrm{~s},{ }^{57}$ which analysed a one year incidence of admission to hospital for myocardial infarction, showed lower age adjusted incidence of admission for those men regularly working at least 10 hours of overtime a week, compared with other workers. Factors associated with the nature of the work seemed to be more important than working hours in predicting admission to hospital for women. The explanation, as in the case of mental health problems, presumably lies at least in part, in the dual role responsibilities of women. Further support for these conclusions was provided by data collected 20 years later in Sweden in the course of a study to examine associations between several aspects of the work environment and admission to hospital for myocardial infarction. ${ }^{58}$ For men, long working hours were associated with a low risk of admission, whereas for women the risk was increased. Similarly, analysis of morbidity and mortality data in Sweden over a 20 year period up to $1983^{59}$ indicated an association between cardiovascular mortality and overtime worked in women but not in men.

Data collected in the United States in the early $1980 \mathrm{~s}^{60}$ failed to find any association between job experiences including working hours and certain risk factors for coronary heart disease, namely blood pressure and serum cholesterol concentrations. However, work hours and deadlines were found to contribute significantly to reported stress and stress related behaviours, particularly in men. The relation between stress and factors such as blood pressure and cholesterol is by no means straightforward and is complicated by individual and time dependent variation. Lack of any direct association is perhaps not surprising. A more recent study of construction managers who regularly worked overtime ${ }^{61}$ did in fact identify increased cholesterol concentrations in this group, who also reported poor psychological health. A range of other determining factors are also likely to have been influential here.

A study carried out in the early $1970 \mathrm{~s}^{62}$ concerned specifically with psychosocial factors and the risk of myocardial infarction was, like those in the $1960 \mathrm{~s}$, somewhat limited in its examination of occupational stressors. This time however, type of occupation, occupational responsibility, and working hours were considered. In a group of 50 patients, $46 \%$ worked more than 60 hours a week compared with $26 \%$ of the controls. The number working between 50 and 60 hours or working on Sundays was slightly higher in the patient group, although the difference here was less obvious. In this study, several behavioural and lifestyle factors were also considered which suggested that those electing to work long hours might be a self selected group in terms of 
personality and behaviour patterns. This question, raised by Buell and Breslow, ${ }^{5 \overline{5}}$ was also a concern of Freidman and Rosenman in the course of their comprehensive research programme on the type A behaviour pattern..$^{\text {th }}$ It has been suggested that those who often work long hours might be especially competitive, or may particularly enjoy their work ${ }^{19}$ both factors which might in some way influence the risk of associated health consequences. Such issues tend to be assessed more often in studies concerned with mental health rather than other types of disorder. However, they may be equally relevant in this context where the development of the physical problem is likely to be mediated by stress.

Recent studies of the relation between long hours and cardiovascular disease are difficult to find. Exceptions are those studies carried out in Japan where the problem of karoshi, sudden unexplained death in relatively young workers, has attracted widespread attention. Uehata" noted that karoshi is a sociomedical term referring to a range of cardiovascular attacks such as strokes, myocardial infarction, or acute cardiac failure resulting from hypertensive or arteriosclerotic disease. It is widely thought that the long working hours which are so much a part of the modern Japanese culture are a major contributory factor. In 1988 it was estimated that one in four of all male Japanese employees worked more than 60 hours a week. ${ }^{175}$ Uehata $^{\text {"nt }}$ studied the behaviour and lifestyle of over 200 karoshi victims and concluded that the problem resulted from a complex interaction of work stress and lifestyle factors, with the fatal attack usually triggered by an acute stressor. Long working hours were judged to play a central part. Interpretation of these data in epidemiological terms is difficult because of the range of conditions encompassed by the single term karoshi. The data are perhaps best viewed therefore as a series of case studies, which suggest the need for future epidemiological investigation. Further, it should be noted that $65 \%$ of these cases regularly worked more than 60 hours a week, with some working more than 50 hours overtime a month and half of their contracted holidays. These hours perhaps represent the extreme in terms of working time although they are not of course unknown elsewhere among certain groups-for example, junior hospital doctors in Europe and the United States.

Consideration of the evidence on cardiovascular disease and long hours suggests that the relation is not a straightforward one. As with the case of mental health disorders working hours seem to play an interactive or perhaps an exacerbating part with other occupational stressors. The influence of sex, of individual factors (motivation, choice, and disposition), and of situational factors (work type, homework interface) are all important in determining the perception of stress and its associated physical responses. Moreover, these physical responses themselves show wide individual variation, which may in turn be linked to dispositional factors. These complicating factors have also been discussed by Sparks et al who carried out meta-analyses on 17 study samples derived from investigations on working hours and health. ${ }^{h i}$ They concluded that significant associations could be identified between hours of work and both physiological and psychological health symptoms. Given the range of factors which may moderate the relation between working hours and health the authors noted that the results of such analyses are, if anything, likely to underestimate the strength of the relation. Evidence currently available, therefore, is undoubtedly sufficient to raise concerns about a possible link between long hours and the risk of significant health outcomes, including cardiovascular disease, particularly when those hours exceed 50 a week. However, much remains to be explored in terms of the nature and interactions of the factors involved.

\section{Performance effects}

The onset of fatigue is perhaps the most obvious direct result of working long hours. However, the concept of fatigue is difficult to define operationally and hence to measure, other than by self report. Most studies have therefore opted to consider fatigue within the context of performance-that is, to measure it indirectly in terms of its effect on performance. Human performance in an occupational setting may itself be considered either directly in terms of outcomes such as productivity and quality assessment, or indirectly in terms of the speed and accuracy in tests which approximate to the work task. These are a relatively recent innovation and the first recorded studies of hours of work and performance focused on direct measures of economic efficiency-such as productivity costs and absenteeism.

An early experiment was carried out in a large Manchester engineering works at the end of the last century.' After discussions with the workers, the management took the somewhat radical step of eliminating early morning (before breakfast) working and also overtime, effectively reducing weekly hours from 53 to 48. Production levels remained about the same and the proportional rise in wages versus output was compensated for by a reduction in fuel costs. An important additional benefit was a considerable reduction in absenteeism. Around the same time a similar approach was adopted by an optical works in Germany. ${ }^{7}$ Here daily hours were reduced from nine to eight, resulting in a $3 \%$ rise in production over a year. The conclusions of these pioneering experiments were supported by the results of a series of studies involving munitions workers during the first world war. ${ }^{\circ}$ Despite being carried out over 80 years ago, these studies have rarely been surpassed in terms of scientific method and attention to detail, and remain one of the most important data sources in the field. During the first world war, munitions workers regularly worked well over 60 hours a week. Reductions of between seven and 20 hours for various groups resulted in a working week of between 50 and 55 hours. The authors of the report noted that in no case did the reduction in hours result in more than an "insignificant 
diminution of total output" and "on average it produced a distinct increase." Production increased gradually over the period of the experiment and was further enhanced by the introduction of 10 minute rest breaks in the mornings and afternoons. Interestingly this finding was supported more recently by the results of a controlled laboratory experiment ${ }^{68}$ in which student volunteers performed cognitive tests under different conditions. As well as showing a relation between the time spent working on the tests and a deterioration in performance, the results indicated that total work output was $6 \%$ better with scheduled rest breaks than without such breaks. The munitions worker study was one of the first systematic demonstrations that reducing working hours does not necessarily reduce productivity and in certain circumstances may increase it.

Since the first world war those findings have been replicated many times in several field studies throughout the world. ${ }^{17}$ For example, a major investigation was conducted in the United States at the end of the second world war to compare the effects of total hours worked in employees who had changed from wartime to peacetime schedules. ${ }^{17}$ Although it was evident that effects were dependent on a range of factors such as type of work and degree of worker control, there was a general trend for longer hours to be associated with lower productivity and higher absenteeism with the optimum schedule seeming to conform to the standard five day, 40 hour week.

In more recent years, there has been a shift in emphasis towards measurement through performance tests designed to simulate work tasks or which involve skills regarded as essential to such tasks, in particular the maintenance of attention. Fieldwork in this area, however, has tended to focus on specific occupational groups such as professional drivers and junior doctors who combine long hours with regular and unpredictable work schedules or with shift work. Similarly, a study of automotive workers in the United States, which showed cumulative negative effects of overtime on negative performance, was also concerned with shift workers many of whom regularly worked at night. Although strictly outside the scope of this review, ${ }^{18} 48$ data from these studies and from numerous laboratory investigations point to the complex relation between long periods of work and impairment of performance. For example, the nature of the task, whether it is routine and monotonous or complex and stimulating, ${ }^{19}$ the motivation of the person ${ }^{20}$ and the presence of other stressors ${ }^{21}$ are all likely to determine the extent of impairment of performance in any given situation. Furthermore, the nature of the impairment-for example, in terms of speed or accuracy ${ }^{20}$ or in terms of the type of error ${ }^{22}$-is likely to vary between situations and occupations.

To date, the methodology which has been developed to investigate these complex relations in the field of shiftwork does not seem to have been applied to the study of overtime effects. Strangely the most reliable information in this field remains that which was initially gathered in the early part of this century and confirmed nearly 50 years ago.

\section{Safety}

Discussion of potential effects on safety involves consideration of two separate issues. The first related to the problem of fatigue and its influence on behaviour associated with safe working practices-for example, the maintenance of attention and the tendency to take risks. In this sense, the question of safety is one particular aspect of human performance. The second issue relates to the problem of prolonged exposure to physical, chemical, and other hazards in the working environment.

The question of fatigue and its effects have been extensively studied relative to shiftwork, in which disruption of normal sleep patterns is clearly of major concern. The problem is a complex one involving consideration of a variety of physiological and social factors which may influence the performance of the worker, and several variables which may influence the nature of accident reporting. Most studies tend to support the view that safety is more likely to be compromised during the night shift, particularly where night working is coupled with extended hours. ${ }^{69} 70$ Little information on the likelihood of increased frequency of accidents occurring - for example, during evening hours after an extended day-can be gleaned from these data. Information from studies of 12 hour shifts does not tend to support the view that an extended day results in higher accident rates. ${ }^{71}$ However, the situation is not directly comparable with that of the extended day as those working 12 hour shifts do so in the expectation of an extended rest period. Further, studies on accident rates tend to compare data with those from a previous rotating eight hour system rather than a normal eight hour day. Data on accident rates associated specifically with long hours, excluding shiftwork, are scarce. There is the information gathered in the munitions workers study, which showed a 2.5 -fold reduction in accidents in women, but not in men, after the reduction in hours of work. However, it should be remembered that these workers also worked shifts, including night shifts, and that the hours in question were excessive by today's standards.

A more recent study in Hong Kong ${ }^{72}$ was able to show a relation between severe hand injuries in factory workers and long working hours, in this case an average working day of nearly 11.5 hours. However, a range of other factors such as lack of training and supervision and worker inexperience were also identified. No analysis was carried out of the time of day at which the accidents occurred and the authors concluded that the nature of the relation between hours worked and accidents was unclear.

Although not directly applicable to the question of overtime work, data relating to groups working irregular or unsocial hours involving phase shifting-for example, junior doctors, ${ }^{73}$ airline flight attendants, ${ }^{74}$ and long distance drivers $^{75}$ - do provide pointers to the issues which remain to be explored in this area. These 
include the relevance of time of day, the importance of rest breaks, and the influence of the type of work on the nature of errors and behavioural change. For example, does fatigue increase risk taking behaviour? Alternatively, do workers opt for a fail safe strategy when they are tired or does this depend on factors such as the perceived importance of the task? Do workers make more skill based or more knowledge based errors at certain times of the day? These and many other questions remain to be explored, together with the most fundamental one of whether hours beyond a certain range do actually result in any reduction in safety as measured by accident rates.

The implications of overtime work for exposure to workplace hazards has been similarly neglected. For example, national and international exposure standards for toxic chemicals, designed to limit exposure to levels below those likely to cause harm, are based on an eight hour day, 40 hour week. Only rarely ${ }^{23}$ has the question of necessary adjustment to accommodate working hours outside this standard week been discussed. The issues involved are complicated and require detailed consideration of factors such as the pharmacokinetics of the toxic effect of individual chemicals. In this field as in many others adequate information is currently absent.

\section{Conclusions and future needs}

This review has considered the weight of the evidence linking long working hours with health problems in the light of the European Community Directive on Working Time. What emerges most strongly is how little information is currently available. The effects of long hours or overtime work seem to have been seriously neglected in favour of an understandable preoccupation with the problems of shiftworking. The results of those studies which have investigated overtime effects suggest grounds for concern but have also highlighted the complex nature of the relation between long hours and health. It is clear that the type and severity of any identified effects are unlikely to be universally applicable, but rather will depend on the characteristics and attitudes of each person, the job requirements, and other aspects of the organisational and cultural climate. Following the example of shiftwork research, carefully controlled studies are required that pay attention to a range of factors which may influence the workers' responses, whether objectively or subjectively assessed.

Most of the studies quoted here which have shown health effects have been concerned with working time beyond 50 hours a week. It is difficult to escape the conclusion that schedules of this nature are detrimental to health and wellbeing. It is also difficult to find evidence that long working hours are beneficial, either to employees or the efficiency of the organisation as a whole. However, currently available data are insufficient to determine exactly how many hours people should be required to work if they are to remain safe and healthy. In particular, more emphasis should be placed on the poten- tial effects of more moderate overtime, between 40 and 50 hours a week.

A further requirement is for the investigation of a wider range of potential health outcomes as many have been virtually ignored. Numerous problems associated with stress may also be associated with long hours. These include gastrointestinal disorders, musculoskeletal disorders, problems associated with depression of the immune system, and psychosomatic complaints likely to reduce efficiency and increase short term absenteeism. Also, the results of one study which investigated the relation between several work factors and fetal death ${ }^{76}$ indicated an increased rate of abortion in women working 46 or more hours a week. Studies of human performance in response to fatigue in overtime situations are surprisingly limited when the attention paid to this in other areas is considered, particularly shiftwork research. Associated with this there has been little consideration of safety concerns either from the legislative point of view or in terms of the changes in worker behaviour likely to result from fatigue. Finally, despite anecdotal evidence and frequent passing references to what may be termed social effects-that is effects on home, family, leisure, and general quality of life-these perhaps most obvious consequences of long hours have not been systematically investigated.

Viewed from a health and safety perspective it is clear that excessive overtime working is not without risk. Given the increasing trend towards such excess a proper assessment of the nature and level of that risk is now urgently required.

1 Council of the European Communities. Concerning certain aspects of the organisation of working time. Council Directive 93/104/EC. Luxembourg: Official Journal of the European Communities, 1993. (No. L 307, 13-12-93, 18-24.)

2 Waterhouse JM, Folkard S, Minors DS. Shiftwork, health and safety: an overview of the scientific literature 1978-90. London: HMSO, 1992.

3 Harrington JM. Shiftwork and health: a critical review of the literature on working hours. Ann Acad Med Singapore 1994; 23:699-705.

4 Mather W. The forty eight hour week: a years experiment and its results. Manchester: Guardian Printing Works, 1984.

5 Abbe E. 1901. Cited in: J Goldmark. Fatigue, efficiency: a study in industry. New York: Russell Sage Foundation, 1912 .

6 Vernon HM. Industrial efficiency and fatigue. In: EL Collis, ed. The industrial clinic, London: John Bale, 1920:51-74.

7 Kogan H. Long hours culture: time for a change. Occup Health 1996;48:48.

8 Bulletin of European studies on time: statistics and news. In: Wedderburn A, ed. Trends in general hours of work. 1996;9:17-29.

9 Austin Knight London. The family friendly workplace: report presented to the conference of the institute of personnel and development. London: Austin Knight, 1995.

10 Higginbottom D. Pay and hours. The essential equation. Report on the United Road Transport Union survey. Chorlton,

11 Fukushima T. Working hours. In: Yoichi I, Hiroshi I, Fukushima T, eds. International comparison of labour statistics. Tokyo: Azuza, 1996.

12 Can long working hours kill? Labour Research 1995;84:21-2. 3 Kasl SV. Mental health and the work environment. $f$ Occup Med 1973;15:509-18.

14 Cooper CL, Marshall J. Occupational sources of stress: a review of the literature relating to coronary heart disease and mental ill health. fournal of Occupational Psychology 1976;49:11-28.

15 Leino P. Symptoms of stress predict musculoskeletal disorders. F Epidemiol Community Health 1989;43:293-300.

16 House JS, McMichael AJ, Wells JA. Occupational stress and health among factory workers. F Health Soc Behav 1979;20: 139-60.

17 Alluisi EA, Morgan BB. Stress performance effectiveness. In: EA Alluisi, EA Fleishman, eds. Human performance, productivity. Vol 3. New Jersey: Lawrence Erlbaun Associates, 1982. 
18 Brown ID. Driver fatigue. Hum Factors 1994;36:298-314.

19 Dinges DF, Kribb NB. Performance while sleepy. Effects of experimentally induced sleepiness. In: TH Monk, ed. Sleep, sleepiness and performance. Chichester: John Wiley, 1991.

20 Craig A. Human engineering: In: JS Warr, ed. The control of vigilance in sustained attention and human performance. Chichester: John Wiley, 1984.

21 Craig A, Cooper RE. Symptoms of acute, chronic fatigue. In: AP Smith, DM Jones, eds. Handbook of human perform ance. Vol 3. State and Trait. London: Academic Press, 1992:12.

22 Williamson AM, Feyer AM. Causes of accidents and time of day. Work and Stress 1995;9:158-64.

23 Goyal R, Krishnan K, Tardif R, Krishnan K, Tardiff R Lapere S, Brodeur J. Assessment of occupational health risk during unusual work shifts: review of the needs and solutions for modifying environmental and biological limit values for volatile organic solvents. Can $\mathcal{F}$ Public Health 1992;183:109-12.

24 Bohle P, Tilley AJ. The impact of night work on psychological well-being. Ergonomics 1989;32:1089-99.

25 Vidacek S, Radosevic-Vidacek B, Kaliterna LJ. Predictive validity of individual difference measures for sleep problems in shiftworkers: preliminary results. In: Oginsk A, Pokorski J, Rutenfranz J, eds. Contemporary advances in shiftwork research. Krakow: Krakow Medical Academy, 1987:277-85.

26 Folkard S, Barton J. The scientific basis for the CEC's proposed directive on working time. Annals of the Polish Academy of Sciences 1992;36:311-3.

27 Schmitt N, Colligan MJ, Fitzgerald M. Unexplained physi$\mathrm{cal}$ symptoms in eight organisations: individual and organical symptoms in eight organisations: individual and organi53:305-17.

28 Oppenheim L. Factors related to occupational stress or burnout among music therapists. fournal of Music Therapy. 1987;24:97-106.

29 Maslach C. Burnout - the cost of caring. New York: Prentice Hall, 1982 .

30 Duffy CA, McGoldrick AE. Stress and the bus driver in the UK transport industry. Work and Stress 1990;4:17-27.

31 Crown S, Crisp AH. Manual of the Crown-Crisp experiential index. London: Hodder and Stoughton, 1979.

32 Daniels K, Guppy A. Stress, social support, and psychological well-being in British accountants. Work and Stress 1995; 9:432-47.

33 Warr PB. The measurement of well-being and other aspects of mental health. Fournal of Occupational Psychology 1990;63:193-210.

34 Goldberg D, Williams P. $A$ users guide to the general health questionnaire, (GHQ). Windsor: Nelson, 1988

35 Ezoe S, Morimoto $K$. Behavioural lifestyle and mental health status of Japanese factory workers. Prev Med 1994;23:98-105.

36 Galambos NL, Walters BJ. Work hours, schedule inflexibility and stress in dual-earner spouses. Can $\mathcal{F}$ Behav Sci ity and stress in

37 Hall E, Johnson JV, Stewart W. Double exposure: the combined impact of the home and work environments on psychosomatic strain in Swed

38 Raggatt PTF. Work stress among long distance coach drivers: a survey and correlational study. Fournal of Organisational Behaviour 1991;12:565-79.

39 Stressing performance IV. A report on peformance, pay, workloads and stress among managerial and professional employees in BT plc. Report of Society of Telecom Executives. London: STE Research c/o IPMS, 1995.

40 Westman M, Eden D, Shirom A. Job stress, cigarette smoking and cessation: the conditioning effects of peer support. ing and cessation: the condition.
Soc Sci Med 1985;20:637-44.

41 Caplan RD, Cobb S, French RP. Relationships of cessation of smoking with job stress, personality and personal support. F Appl Psychol 1975;60:211-9.

42 Kawakami N, Araki S, Haratani T, Hemmi T. Relations of work stress to alcohol use and drinking problems in male and female employees of a computer factory in Japan. Environ Res 1993;62:314-24.

43 Ford CV, Wentz DK. Internship: what is stressful? South Med f 1986;79:595-9.

44 Brown JM, Campbell EA. Sources of occupational stress in the police. Work and Stress 1990;4:305-18.

45 Cooper CL, Davidson MA, Robinson P. Stress in the police service. 7 Occup Med 1988;24:30-6.

46 Turnage JJ, Spielberger CD. Job stress in managers, professional and clerical workers. Work and Stress 1991;5:165-76

47 Maruyama S, Kohno K, Morimotot K. A study of preventive medicine in relation to mental health amon middle management employees (part 2). Effects of long working hours on lifestyles, perceived stress and working life satisfaction among white collar middle managemen
48 Spurgeon A, Harrington JM. Work performance and health of junior hospital doctors: a review of the literature. Work and Stress 1989;3:117-28.

49 Bliese PD, Halverson RR. Individual, nomothetic models of job stress. An examination of work hours, cohesion and well-being. Fournal of Applied Social Psychology. 1996;26: well-being.

50 Watanabe S, Torii J, Shinkai S, Watanabe T. Relationships between health status and working conditions and personalities among VDT workers. Environ Res 1993;61:258-65.

51 Haugland G. An investigation into the effects of working overtime on: a) mental health, b) human performance - a pilo study. [MSc dissertation]. Birmingham: University of Birmingham, 1996.

52 Steptoe A, Fieldman C, Evans O. An experimental study of the effects of control over work pace on cardiovascula responsivity. Fournal of Psychophysiology 1993;7:290-300.

53 Carroll C, Harris MG, Ross G. Haemodynamic adjustments to mental stress in normotensives and subjects with mildly elevated blood pressure. Psychophysiology 1991;28: 438-46.

54 Russek HI, Zohman BL. Relative significance of heredity, diet and occupational stress in coronary heart disease of young adults. Am $\mathcal{F}$ Med 1958;325:266-75.

55 Beull P, Breslow L. Mortality from coronary heart disease in Californian men who work long hours. I Chron Dis 1960;11:615-26.

56 Hinkle LE. Whitney LH, Lehman EW, Dunn J, Benjamin B, King $R$. Occupation, education, and coronary heart disease. Science 1968;161:238-48.

57 Pell S, d'Alonzo CA. Acute myocardial infarction in a large employed population. Report of six-year study of 1356 cases. $\mathcal{F A M A}$ 1963;185:831-41.

58 Alfredsson L, Spetz CL, Theorell T. Type of occupation and near-future hospitalisation for myocardial infarction and some other diagnosis. Int $\mathcal{F}$ Epidemiol 1985;14:378-88.

59 Starrin B, Larsson G, Brenner SO, Levi L, Pettersen IL. Structural changes, ill health and mortality in sweden. 1963-83. A macroaggregated study. Int $¥$ Health Serv 1963-83. A ma:27-42.

60 Sorenson G, Pirie P, Folsom A, Luepker R. Jacobs D, Gillum R. Sex differences in the relationship between work and health. The Minnesota heart survey. $\mathcal{F}$ Health Soc Behav 1985;26:379-94.

61 Sutherland V, Davidson MJ. Using a stress audit: the construction site manager experience in the UK. Work and Stress 1993;7:273-86.

62 Thiel HG, Parker D, Bruce TA. Stress factors and the risk of myocardial infarction. $\mathcal{F}$ Psychosom Res 1973;17:43-57.

63 Friedman M, Rosenman RH. Association with specific over behaviour pattern with blood and cardiovascular findings. FAMA 1959;169:1286-97.

64 Uehata T. Karoshi due to occupational stress-related cardiovascular injuries among middle-aged workers in Japan. Fournal of Science of Labour 1991;67:20-8.

65 Ohta T. Work rules in Japan. International Labour Review 1988;127:627-39.

66 Uehata T. Long working hours and occupational stressrelated cardiovascular attacks among middle-aged workers in Japan. f Hum Ergol (Tokyo) 1992;20:147-53.

67 Sparks K, Cooper CL, Fried Y, Shirom A. The effects of hours of work on health: a meta-analytic review. fournal of Occupational and Organisational Psychology 1997 (in press)

68 Okogbaa OG, Shell RL. The measurement of knowledge worker fatigue. IIE Transactions 1986;335-42.

69 Gold DR, Rogocz S, Bock N, Tosteson TD Baum M Speizer FE. Rotating shift-work, sleep and accidents related to sleepiness in hospital nurses. Am $\mathcal{f}$ Public Health 1992;7:1011-4.

70 Smith L, Folkard S, Poole CJM. Increased injuries on the night shift. Lancet 1994;344:1137-9.

71 Laundry BR, Lees REM. Industrial accident experience of one company of eight and 12 hour shift systems. $\mathcal{F}$ Occup Med 1991;33.903-6.

72 Ong SG, Fung SC, Chow SP, Kleevens JWL. A study of major factors associated with several occupational hand injury in Hong Kong island. Fournal of Society of Occupational Medicine. 1982;32:82-8.

$73 \mathrm{McC}$ all TB. The impact of long working hours on resident physicians. N Engl fै Med 1988;318:775-8.

74 Ono Y, Watanabe S, Kaneko S, Matsumoto K, Miyao M. Working hours and fatigue of Japanese flight attendants. $\mathcal{f}$ Hum Ergol (Tokyo) 1991;20:155-64.

75 Feyer A-M, Williamson AM. Work and rest in the long distance road transport industry in Australia. Work and Stress 1995;9:198-205.

76 McDonald AD, McDonald JC, Armstrong B, Cherry NM Cote R, Lavoie J, et al. Fetal death and work in pregnancy. $\operatorname{Br} \mathcal{F}$ Ind Med 1988;45:148-57. 